\title{
Addressing Barriers to Primary Care Screening and Referral to Prevention for Youth Risky Health Behaviors: Evidence Regarding Potential Cost-Savings and Provider Concerns
}

\author{
Ty A. Ridenour ${ }^{1,3,4}\left(\mathbb{C}^{\circ} \cdot\right.$ Desiree W. Murray $^{2,3} \cdot$ Jesse Hinde ${ }^{1} \cdot$ Cristie Glasheen $^{1} \cdot$ Andra Wilkinson $^{2} \cdot$ Hannah Rackers $^{2}$. \\ Tamera Coyne-Beasley ${ }^{5}$
}

Accepted: 4 October 2021 / Published online: 29 October 2021

(c) Society for Prevention Research 2021

\begin{abstract}
Despite growing evidence and support for co-locating behavioral services in primary care to prevent risky health behaviors, implementation of these services has been limited due to a lack of reimbursement for services and negative perceptions among providers. We investigated potential to overcome these barriers based on new developments in healthcare funding and screening and referral to prevention (SRP) in primary care based on the Consolidated Framework for Implementation Research (CFIR), which could guide future SRP implementation strategies. To investigate the economic need for healthcare-based SRP, we quantified hospital charges to healthcare payors for services arising from adolescent risky behaviors (e.g., substance use, risky sex). Annual North Carolina (NC) hospital charges for these services exceeded \$327 M (2019 dollars), suggesting high potential for cost savings if SRP can curb hospital services associated with risky behaviors. To investigate provider barriers and facilitators, we surveyed $151 \mathrm{NC}$ pediatricians and $230 \mathrm{NC}$ family therapists about their attitudes regarding a recently developed well-child visit SRP with family-based prevention. Both sets of professionals reported widespread need for and interest in the SRP but cited barriers of lack of reimbursement, training, and referrals to/from each other. Physicians, but not family therapists, reported concerns with poor patient or parent compliance. Many barriers could be resolved by co-locating family therapists in pediatric clinics to conduct well-child SRP. Our results support further research to develop business models for payor-funded SRP and CFIR-guided research to develop implementation strategies for primary care SRP to prevent adolescent risky health behaviors.
\end{abstract}

Keywords Prevention $\cdot$ Substance use $\cdot$ Risky sex $\cdot$ Externalizing $\cdot$ Healthcare costs $\cdot$ Primary care $\cdot$ Pediatrics

Despite growing evidence and support for healthcare-based screening and prevention of adolescent risky health behaviors, these services are not widely utilized or researched (Sterling et al., 2012; Tanner-Smith \& Lipsey, 2015). We studied the potential for recent healthcare policy changes and innovations

Ty A. Ridenour

tridenour@rti.org

1 RTI International, 3040 E. Cornwallis Rd PO Box 12194 , 326 Cox Bldg, Research Triangle, NC 27709-2194, USA

2 Child Trends, Franklin St, 1516, Chapel Hill 27514, USA

3 School of Education Or Sheps Center for Health Services Research, University of North Carolina, Chapel Hill, USA

4 School of Pharmacy, University of Pittsburgh, Terrace St, 3501, Pittsburgh 15261, USA

5 Department of Pediatrics, School of Medicine, University of Alabama at Birmingham, Birmingham, USA in screening and referral to prevention (SRP) to overcome historical barriers to two necessary conditions of healthcare SRP: services reimbursement and provider support (Singh et al., 2017; Van Hook et al., 2007). "Risky behaviors" refer to the long-recognized constellation of behaviors including substance use, risky sexual activity, and conduct problems (i.e., externalizing behaviors) which have overlapping etiology factors, can drastically alter adolescents' developmental trajectories, and impede family functioning (Jessor, 2014).

\section{Healthcare Burden Stemming from Risky Health Behaviors}

Risky behaviors incur heavy burden on healthcare by contributing to illness (sexually transmitted infections), injury (fighting or automobile accidents), and other longterm medical conditions (lung cancer) (Cawley \& Ruhm, 
2011). Across all ages, substance use costs the USA over \$740B annually due to treating substance use disorder and related medical conditions, crime, and lost work productivity (National Institute on Drug Abuse, 2020). Unintended pregnancies cost $\$ 21 \mathrm{~B}$ in government public insurance for births, abortions, and miscarriages in 2010 (Sonfield \& Kost, 2015). However, healthcare costs stemming from adolescent risky behaviors have not been researched except for a single 2008 study (to our knowledge) which indicated that US hospitalizations arising from underage drinking cost $\$ 755 \mathrm{M}$ due to motor vehicle accidents, homicides, suicide attempts, and injuries (Kim et al., 2012).

Adolescent risky behaviors are highly prevalent threats to health relative to medical conditions that are traditionally serviced in healthcare such as asthma (7.8\%; Moorman et al., 2011), diabetes (4.0\%; Pettitt et al., 2014), and obesity (20.6\%, Hales et al., 2018). In 2019, about $52 \%$ of US high school seniors had drunk alcohol, $36 \%$ used marijuana, and $12 \%$ used some other illicit drug (Johnston et al., 2020). About $29 \%$ of teens were sexually active, of whom only $54 \%$ used a condom (Redfield et al., 2017). Importantly, high risk and early forms of risky behaviors emerge before high school, demonstrating that at-risk youths can be identified for early indicated prevention (Ridenour et al., 2015). To illustrate, of 2019 US 8th graders, $25 \%$ had drunk alcohol, 10\% smoked cigarettes, and 15\% smoked marijuana (Johnston et al., 2020).

\section{Historical Barriers and Facilitators to Primary Care Screening and Referral to Prevention}

Primary care well-child screening and prevention to reduce adolescent risky behaviors have been recommended by the American Academy of Pediatrics for decades, with increasing support and evidence in recent years (AAP, 2010; Babor et al., 2017; Levy \& Kokotailo, 2011; Ozechowski et al., 2016; Sterling et al., 2012; Tanner-Smith \& Lipsey, 2015). Yet, two historical barriers have precluded implementation of such services: lack of reimbursement and physician concerns regarding burdens on their staff time and costs, lack of training and referral networks, perception that screening tools have high false-positive rates, and fear that screening could alienate patients (Levy et al., 2017; Singh et al., 2017; Sterling et al., 2012; Van Hook et al., 2007).

\section{Recent Developments with Potential to Overcome Historical Barriers}

A potential facilitator of reimbursement for SRP to reduce risky behaviors is the Affordable Care Act mandate that commercial insurance plans and Medicaid/Medicare cover the costs of substance use screening and brief counseling during primary care visits as an essential health benefit (Levy \& Kokotailo, 2011). Yet, many state Medicaid programs have not "activated" these reimbursement codes due to a variety of complex factors, and direct reimbursement of these services in practice has proven challenging (Hinde et al., 2017). A stronger business case for direct reimbursement of SRP services (e.g., healthcare cost burden of youth risky behaviors, cost savings of SRP) may incentivize payors to make use of these reimbursement codes. Long-term benefit cost studies suggest economic returns on investment from prevention in aggregate across multiple settings including healthcare (Kuklinski et al., 2021). However, to our knowledge, short-term savings attributable to reduced healthcare costs have not been evaluated.

Additional recent SRP innovations may address physician concerns such as availability of brief, psychometrically strong screening tools; behavioral specialists embedded into primary care; evidence-based healthcare prevention programs; and evidence that parents and patients support SRP (Galan et al., 2021; Ozechowski et al., 2016; Prado et al., 2019; Ridenour et al., 2015; Sterling et al., 2015). Evidence is accumulating regarding efficacy and effectiveness of healthcarebased screening and referral related to risky behaviors (Moyer \& USPSTF, 2013; Tanner-Smith \& Lipsey, 2015). Recent outcomes studies on coupling evidence-based prevention of risky behaviors with adolescent healthcare services include a well-child SRP with the Family Check-Up intervention, the Familias Unidas universal intervention for families with Hispanic adolescents, and the Guiding Good Choices for Health anticipatory guidance program for parents (Catalano et al., 2018; Galan et al., 2021; Prado et al., 2019).

\section{The Present Studies}

This investigation addressed both of the aforementioned necessary conditions for SRP. First, we estimated the burden of hospital charges to healthcare payors for services arising from risky behaviors (toward building a business case for healthcare-based SRP). Second, we evaluated providers' perceptions of SRP barriers and facilitators, based on a recently developed SRP for well-child visits that uses a preteen self-report screening tool of propensity for risky health behaviors (not asking about the behaviors per se) given by behavior specialists who interpret scores, make "referrals," and provide family-based prevention (Galan et al., 2021; Ridenour et al., 2015).

The Consolidated Framework for Implementation Research (CFIR; Damschroder et al., 2009; Stanhope et al., 2018) guided our study foci because its domains span economic factors and provider readiness within a broad context of factors that are germane to SRP implementation, including factors that are external to providers' workplaces (outer setting), factors within providers' workplaces (inner setting), and characteristics of the 


\begin{tabular}{|c|c|c|c|c|}
\hline $\begin{array}{l}\text { Characteristics of } \\
\text { The Intervention }\end{array}$ & $\begin{array}{l}\text { Inner } \\
\text { Setting }\end{array}$ & $\begin{array}{l}\text { Outer } \\
\text { Setting }\end{array}$ & $\begin{array}{l}\text { Individuals Involved } \\
\text { (Providers) }\end{array}$ & $\begin{array}{l}\text { Implementation } \\
\text { Process }\end{array}$ \\
\hline $\begin{array}{l}\text { - Feasibility } \\
\text { - Perceived efficacy } \\
\text { (including follow up } \\
\text { referrals) }\end{array}$ & $\begin{array}{l}\text { - "Fit" of intervention } \\
\text { within workflow and } \\
\text { systems } \\
\text { - Time constraints } \\
\text { - Competing priorities } \\
\text { - Other resources }\end{array}$ & $\begin{array}{l}\text { - "Fit" of intervention } \\
\text { within workflow and } \\
\text { systems } \\
\text { - Time constraints } \\
\text { - Competing priorities } \\
\text { - Other resources }\end{array}$ & $\begin{array}{l}\text { - Provider skills and } \\
\text { competencies } \\
\text { (including lack of } \\
\text { training } \\
\text { - Provider attitudes and } \\
\text { beliefs (including }\end{array}$ & $\begin{array}{l}\text { - Screening logistics } \\
\text { - Administrative } \\
\text { protocol }\end{array}$ \\
\hline
\end{tabular}

Fig. 1 Implementation elements of the consolidated framework for implementation research applied to screening and referral for prevention of risky health behaviors. Based on Damschroder et al. (2009). Characteristics of the intervention encompass key stakeholders' perceptions of an intervention (e.g., feasibility of implementation, its adaptability to a practice) and the intervention itself (e.g., underlying evidence, complexity). Inner setting refers to characteristics of a pediatric practice that are germane to intervention implementation (e.g., staff values and priorities, readiness and resistance to the new inter-

providers themselves (Fig. 1). Perhaps superseding all other implementation factors in necessity for SRP is funding (an outer setting factor). As mentioned, cost-savings from prevention services may incentivize healthcare payor investment in efficacious SRP (Levy et al., 2017; Singh et al., 2017). Hence, as a first step toward evaluating potential cost savings to payors (e.g., Medicaid) from SRP-initiated prevention, we estimated healthcare costs arising from adolescent risky behavior. However, funding is not the only necessary condition; provider support also is required. Pediatricians, surveyed about the well-child SRP, and family therapists, surveyed about family-based prevention, reported on their perceptions of barriers and facilitators from CFIR's outer setting, inner setting, and provider factors including the importance of SRP funding.

Our studies occurred in North Carolina (NC) because it appears primed for advancing SRP adaptation. NC Medicaid recommends substance use assessment (NC DMA, 2018). Statewide scale-up of the Triple $\mathrm{P}$ parenting-based prevention program began in 2017 and could be a referral source for pediatricians (O'Connor, 2019). UNC-Chapel Hill scientists support state-wide implementation of Triple $\mathrm{P}$, and many community leader teams include a pediatrician (FPGCDI, 2020). Leading NC healthcare systems screen for adverse childhood experiences during pediatric visits. An NC grantee is funded by CMS to "reduce expenditures and improve the quality of care for children under 21 years of age covered by Medicaid through prevention ... of behavioral and physical health needs" (CMS Innovation Center, 2020). Finally, research is vention). Outer setting is composed of influences that are external to the practice that impact the implementation of an intervention (e.g., patient needs, network with referral sources, reimbursement for the service). Characteristics of individuals focus on staff within the practice (e.g., self-efficacy to conduct the intervention, commitment to the practice). Implementation process includes four processes involved with organizational change: planning for implementation, engaging individuals who conduct the intervention, executing the implementation, and reflecting and evaluating the implementation

ongoing in NC to test the feasibility of the well-child SRP on which our provider surveys were based (Saavedra \& Schilling, NIH CTSA grant 550KR231925, 2020).

\section{Study 1: NC Hospital Charges Associated with Youth Risky Health Behaviors}

Study 1 began to address the gap in outer setting evidence on whether preventing youth risky behaviors may be strategic for healthcare payors in terms of costs. Specifically, the healthcare cost burden was estimated in terms of annual hospital visits and charges associated with adolescent risky behavior. Visits and charges were estimated separately by age group, risky behavior type, and hospital setting to understand their relative impact on healthcare burden and where potential cost-savings might accrue. Post hoc, we estimated the potential investment that would be required of payors to reduce services and charges that stem from youth risky behavior (i.e., well-child visit SRP) based on a recent SRP clinical trial and Medicaid fee schedules.

\section{Method}

\section{Sample}

We analyzed all $2012 \mathrm{NC}$ discharges for patients ages 9 to 18 (prior to surging healthcare costs due to synthetic opioids) 
using Healthcare Cost and Utilization Project (HCUP) Ambulatory Surgery and Services Database (hospital outpatient visits), Emergency Department Database (ED visits that do not result in an inpatient stay), and Inpatient Database (HCUP, 2019). HCUP is the most comprehensive, allpayer dataset available for hospital-related services. Some observations were dropped $(<0.1 \%)$ due to a missing ICD-9 code, negative total charge, county identifier, or expected insurance source. The final sample was 29,981 inpatient hospital, 377,582 emergency department, and 563,656 ambulatory surgery and outpatient hospital discharges.

\section{Instrumentation}

For each hospital discharge, data included ICD-9 diagnostic codes, procedure codes and total charges for the services. Data did not include actual hospital costs to provide the services or final payments made by the payor for those services. The HCUP 2012 cost-to-charge ratio indicated that on average, costs for services were $46 \%$ of the charges with significant variation across hospitals within a state (Agency for Health Research and Quality, 2012).

\section{Procedure}

Determination of which hospital discharges were related to risky behaviors was based on ICD-9 diagnostic codes. First, two epidemiologists selected categories of ICD-9 codes that had even a slim possibility of resulting from risky behavior, based on Clinical Classification Software codes: sexual activity, alcohol or other substance use-related codes, psychiatric disorders, poisoning, some "external cause of injury" codes (e.g., motor vehicle traffic, firearms), and suicide. The resultant 2,477 ICD-9 codes were then independently rated by a senior pediatrician and a pediatric resident as to whether "the diagnosis likely stemmed from risky behavior for the large majority of patients". See Study 1 Supplemental Materials for a list of the risky behavior codes and pediatrician ratings. Interrater reliability kappa was 0.74 (adequate) with agreement on $89.5 \%$ of ICD-9 codes. In cases of disagreement, the senior pediatrician determined whether a code likely stemmed from risky behavior. A total of 1,863 ICD-9 codes were considered to stem largely from risky behavior.

\section{Analyses}

Analyses consisted of summing number of visits or charges by setting (inpatient, outpatient, and emergency department), age group (9-13 vs. 14-18), and type of risky behavior. Age groups were analyzed separately because adherence to wellchild visit guidelines drops after 12 (Selden, 2006) and risky behavior incidence rises during adolescence (Johnston et al.,
2020). Charges and visits associated with risky behaviors were compared to all-cause discharges to understand the relative burden of risky behaviors. To facilitate interpretation, the 2012 charges were inflated to 2019 dollars using the medical consumer price index for 2019, which inflated the charges by about 20\% (US Bureau of Labor Statistics, 2019).

Each HCUP visit could include up to 21 ICD-9 codes, with the first code being the most germane reason for the visit and relevance of codes descending per their order (providing a crude metric of how relevant risky behavior was to a visit). Whether a visit was attributed to risky behavior in analyses was coded in three ways to inform strategies of potential future cost savings studies and as simple sensitivity analyses: only the first ICD-9 code, any of top three codes, or any of the 21 codes. Unless otherwise noted, results were based on using the top three codes in attempt to capture all visits in which risky behavior was a germane factor. Charges associated with specific risky behavior types (e.g., substance use vs. risky sex) were not mutually exclusive because if a single visit involved multiple risky behaviors, its related charges were counted toward each behavior type. In contrast, when charges were aggregated across all behavior types, charges for a visit with more than one risky behavior ICD-9 code were counted only once.

\section{Results}

For all ages, ICD-9 codes related to risky behaviors were one of the first three codes in $34 \%$ of inpatient hospitalizations, $8 \%$ of emergency room visits, and $7 \%$ of outpatient visits. Prevalence of visits related to risky behaviors was 3.8 to 33 times more prevalent in older than younger youth, depending on setting and how relevant a risky behavior was to the visit (Table 1, upper section). For both age groups, greater proportions of inpatient visits involved risky behavior compared to emergency room and outpatient visits. Larger proportions of hospital charges also were associated with risky behaviors (first three codes) for older youths compared to younger youths: $33.0 \%$ of inpatient charges (versus 9.7\%), $20.9 \%$ of emergency department charges (versus $4.4 \%$ ), and $11.0 \%$ of outpatient charges (versus 1.4\%) (Table 1, lower section) (all $p<.001$ ).

Table 2 presents summed visits and hospital charges by type of risky behavior (not mutually exclusive categories) compared to all-cause discharges. Over $\$ 327 \mathrm{M}$ was charged for any visit with a risky behavior-related code in the top three codes, accounting for over $10 \%$ of total hospital charges for ages 9-18 (Table 2, right-most column). Healthcare charges related to a risky behavior in any of the 21 codes were over $\$ 456.8 \mathrm{M}$, nearly $15 \%$ of total hospital charges for ages 9-18. Among types of risky behavior codes for ages 9-18, substance abuse and sexual activity accrued the most charges, about $\$ 110 \mathrm{M}$ and $\$ 155 \mathrm{M}$ (2019 dollars), 
Table 1 Prevalence of, and hospital charges likely stemming from, youth risky health behaviors in North Carolina

\begin{tabular}{|c|c|c|c|c|c|c|}
\hline & \multicolumn{6}{|c|}{ Prevalence of Visits Associated with Risky Health Behavior ICD-9 Codes } \\
\hline & \multicolumn{2}{|l|}{ Inpatient } & \multicolumn{2}{|c|}{ Emergency department } & \multicolumn{2}{|l|}{ Outpatient } \\
\hline & $9-13$ years & $14-18$ years & $9-13$ years & $14-18$ years & $9-13$ years & $14-18$ years \\
\hline $\begin{array}{l}\text { Risky behavior is pri- } \\
\text { mary reason for visit }\end{array}$ & $<1.0 \%(n=74)$ & $32.9 \%(n=6,885)$ & $<1.0 \%(n=562)$ & $5.3 \%(n=11,878)$ & $<1.0 \%(n=934)$ & $7.2 \%(n=23,756)$ \\
\hline $\begin{array}{l}\text { Risky behavior is in top } 3 \\
\text { reasons for visit }\end{array}$ & $8.4 \%(n=756)$ & $45.3 \%(n=9,488)$ & $1.5 \%(n=2,268)$ & $12.2 \%(n=27,376)$ & $1.0 \%(n=2,328)$ & $11.6 \%(n=38,091)$ \\
\hline $\begin{array}{l}\text { Risky behavior is among } \\
\text { any reason for visit }\end{array}$ & $14.3 \%(n=1,291)$ & $53.8 \%(n=11,282)$ & $2.1 \%(n=3,220)$ & $15.8 \%(n=35,230)$ & $1.0 \%(n=3,188)$ & $13.7 \%(n=45,026)$ \\
\hline Total visits for any reason & $n=9,024$ & $n=20,957$ & $n=153,967$ & $n=223,615$ & $n=234,644$ & $n=329,012$ \\
\hline & \multicolumn{6}{|c|}{ Total charges for visits associated with risky health behavior ICD-9 codes (2019 dollars) } \\
\hline $\begin{array}{l}\text { Risky behavior is in top } \\
3 \text { reasons for visit (\% of } \\
\text { all charges) }\end{array}$ & $\begin{array}{l}\$ 14,411,866 \\
(5.5 \%)\end{array}$ & $\begin{array}{l}\$ 131,150,217 \\
(25.0 \%)\end{array}$ & $\begin{array}{l}\$ 10,445,170 \\
(3.1 \%)\end{array}$ & $\begin{array}{l}\$ 90,990,069 \\
(14.0 \%)\end{array}$ & $\begin{array}{l}\$ 5,163,831 \\
(1.0 \%)\end{array}$ & $\begin{array}{l}\$ 75,644,258 \\
(8.3 \%)\end{array}$ \\
\hline $\begin{array}{l}\text { Risky behavior is in any } \\
\text { of reason for visit (\% of } \\
\text { all charges) }\end{array}$ & $\begin{array}{l}\$ 25,568,413 \\
(9.7 \%)\end{array}$ & $\begin{array}{l}\$ 173,477,524 \\
(33.0 \%)\end{array}$ & $\begin{array}{l}\$ 15,035,007 \\
(4.4 \%)\end{array}$ & $\begin{array}{l}\$ 135,876,610 \\
(20.9 \%)\end{array}$ & $\begin{array}{l}\$ 7,327,951 \\
(1.4 \%)\end{array}$ & $\begin{array}{l}\$ 99,494,316 \\
(11.0 \%)\end{array}$ \\
\hline $\begin{array}{l}\text { Charges for all hospital } \\
\text { visits }\end{array}$ & $\$ 264,101,783$ & $\$ 524,972,871$ & $\$ 340,400,082$ & $\$ 649,537,506$ & $\$ 530,200,832$ & $\$ 907,742,967$ \\
\hline
\end{tabular}

Reason for a visit is based on ICD-9 codes that reflect risky health behaviors. Up to 21 ICD diagnoses per patient visit are included in the HCUP database (Healthcare Cost \& Utilization Project, 2019)

$n$ number of visits, not individuals

respectively. Patterns in risky behavior visits and charges varied by age group (Table 2, upper section). For ages 9-13, externalizing behavior visits were more frequent and costly than other behaviors whereas substance use and sexual activity were most frequent and costly for ages $14-18$.

\section{Post Hoc Analyses}

Based on the large healthcare burden from youth risky behaviors, a cost-savings model might incentivize payors to invest in SRP if the cost is offset by reduced hospital services and charges for risky behaviors. A cost-savings model requires the reduction in hospital charges to exceed a payors' SRP investment. To our knowledge, no data exist regarding the impact on healthcare services or charges that can be attributed to prevention programs' reduction of risky behaviors. Likewise, no estimates exist regarding the initial investment that would be required of healthcare payors to fund SRP. Thus, we estimated cost-savings needed to yield a return on investment in a specific SRP that uses the Youth Risk Index screening tool and the Family Check-Up intervention (see its description in Study 2 Supplemental Materials; Galan et al., 2021; Ridenour et al., 2015). Costs were based on 2019 Medicaid fee schedules for services of SBIRT and family therapy, which resemble this SRP. Costs based on this SRP are likely overestimated as they are based on SRP enrollment in a recent clinical trial, which was based on consenting participants (not the general population), and enrollment was high (93.5\%).
Our assumptions were as follows. The estimated number of youths receiving SRP was based on all NC 12-year-olds, about 108,273 (NC Demographic Statistics, 2020; North Carolina Population, 2020), because attendance of wellchild visits drops rapidly after age 12 (Selden, 2006). The rate of youths screening "at risk" was based on the Youth Risk Index ${ }^{\odot}$ screening tool national standardization sample rate of moderate or high risk (32.8\%). In the clinical trial, 93.5\% of parents of "at-risk" youths enrolled in Family Check-Up, nearly all completed both sessions, and 36.5\% of the completers received a mean 7.62 additional sessions ( $S D=9.07$; nearly all sessions were family counseling). Thus, costs for SRP based on 2019 NC Medicaid schedules were $\$ 24$ each for screening (HCPCS code H0049) of 108,273 NC 12-year-olds; $\$ 480$ per Family Check-Up for $32.8 \%$ of youths who screen at risk (family therapy code CPT 90,847 with additional time covered by CPT 99,354), assuming a $93.5 \%$ enrollment rate; and finally $\$ 107.19$ per additional counseling session (CPT 90,847) for an average of 7.62 sessions for $36.5 \%$ of FCU completers (American Society of Addiction Medicine, 2017; https://therathink. com/cpt-code-90847/).

In sum, SRP with the Family Check-Up could cost $\$ 28,436,277$ based on NC Medicaid fees for family therapy, about $8.7 \%$ of annual hospital charges related to risky behaviors. The estimated annual cost for screening is $\$ 2,598,552$ in 2019 dollars (108,273 youths at $\$ 24$ per screen). Assuming 32.8\% of youths score at risk and $93.5 \%$ of their parents complete the 
Table 2 Hospital visits and charges related to risky health behavior in North Carolina (2019 dollars)

\begin{tabular}{|c|c|c|c|c|c|c|}
\hline \multirow{2}{*}{$\begin{array}{l}\text { Risky Behavior in Top } 3 \\
\text { ICD Codes for Visit }\end{array}$} & \multicolumn{2}{|c|}{$9-13$ years old } & \multicolumn{2}{|l|}{$14-18$ years old } & \multicolumn{2}{|l|}{ Total ages 9-18 } \\
\hline & No. of Visits & Charges & No. of Visits & Charges & No. of Visits & Charges \\
\hline Substance abuse & 1,167 & $\$ 6,652,019$ & 28,287 & $\$ 103,232,484$ & 29,454 & $\$ 109,884,503$ \\
\hline Sexual activity & 825 & $5,092,759$ & 39,300 & $149,433,183$ & 40,125 & $154,525,980$ \\
\hline Externalizing behavior & 5,643 & $25,781,469$ & 8,682 & $41,236,031$ & 14,325 & $67,017,500$ \\
\hline Gun-related injury & 35 & 254,484 & 273 & $1,919,730$ & 308 & $2,174,214$ \\
\hline Poisoning & 340 & $1,167,431$ & 1,871 & $11,479,880$ & 2,211 & $12,648,464$ \\
\hline Motor vehicle accidents & - & - & - & 44,664 & - & 44,664 \\
\hline $\begin{array}{l}\text { Any risky behavior in } \\
\text { Top } 3 \text { (percent of all } \\
\text { admissions*) }\end{array}$ & $5,352(1.4 \%)$ & $\$ 30,020,867(2.7 \%)$ & $74,955(13.1 \%)$ & $\$ 297,784,544(14.3 \%)$ & $80,307(8.3 \%)$ & $\$ 327,805,232(10.2 \%)$ \\
\hline $\begin{array}{l}\text { Any risky behavior in } \\
\text { any code (percent of all } \\
\text { admissions*) }\end{array}$ & $7,699(1.9 \%)$ & $\$ 47,931,371(4.2 \%)$ & $91,538(16.0 \%)$ & $\$ 408,848,450(19.6 \%)$ & $99,237(10.2 \%)$ & $\$ 456,779,762(14.2 \%)$ \\
\hline \multirow{2}{*}{$\begin{array}{l}\text { *All admissions for any } \\
\text { code }\end{array}$} & 397,635 & $\$ 1,134,702,697$ & 573,584 & $\$ 2,082,253,344$ & 971,219 & $\$ 3,216,954,596$ \\
\hline & \multicolumn{6}{|c|}{ SRP cost estimates (North Carolina 12-year-olds) } \\
\hline $\begin{array}{l}\text { Screening for NC } \\
12 \text {-year-olds }\end{array}$ & 108,273 & $\$ 2,598,552$ & & & & \\
\hline $\begin{array}{l}\text { FCU reimbursed as a } \\
\text { NC Medicaid family } \\
\text { therapy }^{b}\end{array}$ & 33,205 & $\$ 15,938,400$ & & & & \\
\hline Additional sessions ${ }^{\mathrm{c}}$ & 12,120 & $\$ 9,899,468$ & & & & \\
\hline
\end{tabular}

As more than one reason could be coded for any visit, results by behavior type are not mutually exclusive. To illustrate, summing charges associated with the specific behavior types $(\$ 346,295,325$ for Top 3 Codes) is $\$ 18,490,093$ greater than summing costs by counting each visit only once (i.e., $\$ 327,805,232$ ). Charges are in 2019 dollars (increased by $20.12 \%$ from 2012 charges, based on the medical consumer price index (US Bureau of Labor Statistics, 2019). Data are suppressed if the number of visits $<10$

FCU Family Check-Up

${ }^{a}$ Assumes 108,273 NC 12-year-olds (NC Demographic Statistics, 2020; North Carolina Population, 2020) and \$24.00 fee per screening (e.g., HCPCS code H0049; American Society of Addiction Medicine, 2017)

${ }^{\mathrm{b}}$ Assumes a Medicaid fee for completing FCU of family therapy sessions (CPT 90,847 with add-on of 99,354 or \$480 https://therathink.com/cptcode-90847/), 32.8\% referral rate (per recent U.S. standardization scores of the Youth Risk Index@; Ridenour et al., 2015), and 93.5\% enrollment rate (Galan et al., 2021)

${ }^{\mathrm{c}}$ Cost estimate is based on Medicaid fee for family therapy (\$107.19 per session, CPT 90,847) and a mean 7.62 sessions for $36.5 \%$ of FCU completers (Galan et al., 2021)

Family Check-Up, prevention would cost $\$ 15,938,400$ ( $\$ 480$ per 33,205 families). Finally, 7.62 additional counseling sessions for $36.5 \%$ of Family Check-Up recipients would cost $\$ 9,899,325$ (at $\$ 107.19$ per session). Importantly, our estimates are from the payor perspective and do not account for provider costs such as start-up costs (e.g., training) or "no-shows." Even so, SPR offers high potential to yield costs savings if it reduces hospital charges by at least $8.7 \%$.

\section{Study 2: NC Provider Perceptions of Screening and Referral to Prevention}

Study 1 suggested SRP may provide cost savings if it reduces healthcare charges. However, the feasibility of this strategy depends on perceptions and readiness of well-child providers. We surveyed pediatricians (about conducting the SRP) and family therapists (about delivering family-based prevention) regarding their perceived readiness, barriers, and facilitators for SRP. Survey items asked about provider perceptions within the context of CFIR inner setting, outer setting, and provider factors in part to inform future implementation strategies.

\section{Methods}

\section{Procedure}

Study invitations followed a stratified two-stage sampling design, based on providers' practice zip codes. Zip codes were first parsed into NC's three geographical regions: 
Mountain, Coastal, and the Piedmont region between them. The next stratification was by urban (including suburban) versus rural locations based on Census coding. To ensure adequate representation of the less populous regions, all the eligible professionals in the less populous strata were invited to participate whereas fewer professionals were invited from the more populous strata. Email invitations to complete an on-line survey were sent to randomly chosen 536 pediatricians of the 1329 members of the NC Pediatric Society and 677 of the 983 members of the NC Association for Marriage and Family Therapists. Every respondent was accepted into the study until preset " $n$ " per stratum was met to match the NC distributions of professionals (further weighting of data was not used). Respondents were compensated $\$ 50$.

\section{Sample}

Pediatrician $(n=151)$ and family therapist $(n=230)$ demographics were similar but differed statistically (Table 3): mostly female $(77.5 \%$ and $67.0 \%$, respectively, $p<0.001$ ), non-Hispanic Caucasian $(78.1 \%, 83.9 \%)$, and in their early $40 \mathrm{~s}(\bar{X}=44.3, S D=10.7 ; \bar{X}=41.7, S D=13.1, p<0.05)$. They resembled NC pediatricians and US family therapists, respectively, in terms of gender $(73 \%, 71 \%$ female) and race $(73 \%, 86 \%$ non-Hispanic Caucasian) (American Board of Pediatrics, 2017; Beck et al., 2017; McGee \& Fraher, 2012). Most pediatricians specialized in adolescent care (62\%); about half of family therapists specialized in child therapy $(51.7 \%)$ or parenting $(54.8 \%)$. Consistent with study strata, pediatricians and family therapists respectively $(p=0.57)$ practiced mostly in urban areas only $(62.3 \%$, $57.0 \%)$, then in rural areas only $(24.5 \%, 27.0 \%)$, and both urban and rural $(13.2 \%, 16.1 \%)$. Clients of pediatricians and family therapists, respectively, were similar in terms of race and ethnicity: Caucasian $(40.9 \%, 53.0 \%)$, African American $(31.3 \%, 29.1 \%)$, Latinx $(20.1 \%, 12.4 \%)$, and Asian (5.7\%, 2.6\%); low income: $<\$ 30,000 /$ year $(39.2 \%$, $43.8 \%)$; and gender $(51.0 \%, 52.3 \%$ female; $8.5 \%, 9.3 \%$ transgender or other).

\section{Instrumentation}

Survey items queried barriers and facilitators of implementing SRP for risky health behaviors (Ridenour et al., 2015; Van Hook et al., 2007), including provider perceptions, skills, needed training, and costs/reimbursement. Survey items were stand-alone rather than a summative measure to minimize participant burden and included close- and open-ended questions (Study 2 Supplemental Materials). Slightly different questions were posed to pediatricians and family therapists, reflecting their roles in providing SRP or intervention.

\section{Analysis}

Frequencies and $\chi^{2}$ tests comparing pediatricians to family therapists on similar barriers/facilitators were computed using SAS 9.4. Two study team members coded open-ended responses in alignment with CFIR domains and in consultation with the first and second authors; all codes required consensus agreement among the four team members, e.g., response categories for "What impediments could block using this [SRP] in your [pediatric] practice," included lack of staff time (inner setting), perceived low parental support (provider factors), lack of referral sources (outer setting), and lack of staff buy-in (provider factors). $\chi^{2}$ tests of responses to open-ended questions were conducted after responses were coded. Study 2 Supplemental Materials present detailed frequencies, including all response categories for open-ended questions.

\section{Results}

Participants offered a range of services that resemble SRP (Table 3). Most pediatricians (95.4\%) and family therapists (83.6\%) would consider participating in research to test SRP $(p<0.001$; Table 4). Regarding perceived need for SRP, both professions reported nearly $1 / 3$ of youths they service engage in risky behaviors ( $p=0.75$; Table 4$)$. Pediatricians reported "many or most" of their patients would benefit from SRP (72.1\%, Study 2 Supplemental Materials), and family therapists reported an average of $45.4 \%(\mathrm{SD}=32.8 \%)$ of their child services involve behavior problems. About $1 / 3$ of both professions offered no services to prevent risky behaviors ( $p=0.77$; Table 3 ). Only $12.6 \%$ of pediatricians conducted risky behavior screenings, and $11.3 \%$ referred patients to external prevention providers (Table 3). Nearly all pediatricians (86.6\%) would be more likely to provide SRP if it was reimbursed.

The most common pediatrician barriers were lack of time (68.2\%), perceived lack of parent support (25.2\%), concerns about confidentiality and youths' honesty in reporting risky behaviors (17.2\%), and not knowing where to refer patients $(19.2 \%)$. The first three concerns were not prevalent for family therapists $(8.7 \%, 2.6 \%$, and $2.6 \%$, respectively, all $p<0.001$ ) whereas referral sources were an equally prevalent barrier (19.6\%). Family therapists' most prevalent barriers were funding concerns $(25.7 \%)$ and staff training $(12.2 \%, p<0.001$ compared to pediatricians). Efficient SRP processes (e.g., brief screening tool, integrated workflow) were pediatricians' most common facilitator $(66.9 \%)$ followed by availability of referral sources (26.5\%). Family therapists' most common facilitators were getting referrals (19.6\%), reimbursement (17.8\%), and training (44.8\%), the latter of which $91.3 \%$ were willing to receive. 
Table 3 Provider demographics and existing services for prevention and treatment of risky health behaviors

\begin{tabular}{|c|c|c|}
\hline & $\begin{array}{l}\text { PEDIATRICIANS } \\
(N=151)\end{array}$ & $\begin{array}{l}\text { FAMILY } \\
\text { THERAPISTS } \\
(N=230)\end{array}$ \\
\hline & Mean (SD) or $\%$ & Mean (SD) or $\%$ \\
\hline Gender ( $\%$ female $)^{*}$ & 77.5 & 67.0 \\
\hline $\operatorname{Age}^{* *}$ & $44.3(10.7)$ & $41.7(13.1)$ \\
\hline Race $^{* * *}$ Caucasian (non-Hispanic) & 78.1 & 83.9 \\
\hline African American (non-Hispanic) & 8.6 & 10.0 \\
\hline Latinx & 2.6 & 3.0 \\
\hline Asian & 9.3 & 0.4 \\
\hline Other/multi-race & 1.3 & 2.6 \\
\hline \multicolumn{3}{|l|}{ Existing services to prevent risky behaviors } \\
\hline None & 32.5 & 33.9 \\
\hline Physician counseling & 39.1 & 0.4 \\
\hline Anticipatory guidance & 14.6 & 0.0 \\
\hline Screening & 12.6 & 1.3 \\
\hline External referral & 11.3 & 5.7 \\
\hline Internal referral & 4.6 & 0.4 \\
\hline Print materials & 7.9 & 0.4 \\
\hline Therapy & 0.7 & 37.4 \\
\hline Psychoeducation & 0 & 26.5 \\
\hline Assessments & 0.7 & 3.9 \\
\hline Other & 8.6 & 17.8 \\
\hline \multicolumn{3}{|l|}{ Existing services to treat risky behaviors } \\
\hline Individual therapy & & 54.3 \\
\hline Family therapy & & 39.6 \\
\hline Group therapy & & 9.6 \\
\hline Psychoeducation & & 22.6 \\
\hline Psychiatric services/med management & & 2.6 \\
\hline Consultation and assessment & & 6.5 \\
\hline Care management & & 0.9 \\
\hline Refer to other programs/services & & 5.7 \\
\hline Intensive services & & 12.2 \\
\hline Addiction services & & 4.3 \\
\hline None & & 21.7 \\
\hline Other & & 4.8 \\
\hline
\end{tabular}

Data from self-reported surveys of providers in North Carolina

${ }^{*} \chi^{2}=11.25, p<.001 ; * *$ One-way ANOVA $F=4.14, p<.05 ; * * *$ Fisher's exact $\chi^{2}=19.40, p<.001$

\section{Discussion}

In sum, study results suggested that high costs stemming from adolescent risky behaviors and recent developments in healthcare-based prevention may be helpful in advancing research on funding and implementing SRP. Over $10 \%$ of $\mathrm{NC}$ adolescents' hospital healthcare charges (over \$327 M) are associated with risky health behaviors, suggesting that reducing these costs through prevention may be an incentive for payors to directly reimburse SRP (a requisite reported by nearly all pediatricians). Pediatricians and family therapists expressed a high need and interest in providing SRP. One strength of our studies is they both represented an entire state during the same time span, thus directly addressing payor catchment areas (e.g., NC Medicaid), and they included diversity of locales (urban and rural; mountainous, agricultural, coastal), local economies, and healthcare systems. Another strength of the studies is that the facilitators and barriers were aligned with CFIR to inform future implementation research to develop SRP for well-child visits (Vendetti et al., 2017). Lastly, charges calculations used observed data rather than being simulated. 
Table 4 Barriers and facilitators to SRP provision by provider type and CFIR domain

PEDIATRICIANS $(N=151)$ FAMILY THERAPISTS $(N=230)$

\begin{tabular}{|c|c|c|}
\hline \multicolumn{3}{|l|}{ Characteristics of screening/intervention (and implementation process) } \\
\hline Facilitator: available in other languages* & $2.6 \%$ & $0.0 \%$ \\
\hline \multicolumn{3}{|l|}{ Inner setting } \\
\hline Facilitator: leadership support & 1.3 & 2.6 \\
\hline Barrier: lack of provider time $* * *$ & 68.2 & 8.7 \\
\hline \multicolumn{3}{|l|}{ Outer setting } \\
\hline Facilitator: more likely to use SRP if funding available ${ }^{a, b}$ & 86.6 & 17.8 \\
\hline Facilitator: having referral resources & 26.5 & 19.6 \\
\hline Facilitator: $\%$ of clients engaging in risky behaviors ${ }^{\mathrm{a}}$ & 32.7 & 30.8 \\
\hline Barrier: lack of access to referral resources** & 19.2 & 9.6 \\
\hline Barrier: patient transportation needs* & 4.6 & 0.9 \\
\hline Barrier: lack of insurance reimbursement/other funding concern** & 12.6 & 25.7 \\
\hline \multicolumn{3}{|l|}{ Provider factors } \\
\hline Facilitator: staff training $* * *$ & 6.6 & 44.8 \\
\hline Facilitator (buy in): willing to receive SRP training ${ }^{\text {a }}$ & - & 91.3 \\
\hline Facilitator (buy-in): would consider participating in an SRP study***a & 95.4 & 83.6 \\
\hline Barrier: perceived lack of parental support ${ }^{* * *}$ & 25.2 & 2.6 \\
\hline Barrier: perceived poor compliance (by patients or parents) ${ }^{* * *}$ & 17.2 & 2.6 \\
\hline Barrier: lack of staff buy-in & 6.0 & 6.1 \\
\hline Barrier: need for staff training** & 3.3 & 12.2 \\
\hline \multicolumn{3}{|l|}{ Implementation process (and inner setting) } \\
\hline Facilitator: brief screening tools or well-integrated workflow*** & 66.9 & 7.0 \\
\hline
\end{tabular}

Most facilitators and barriers were identified through coding of responses to open-ended questions (see Study 2 Supplemental Materials), except for those noted otherwise

${ }^{a}$ Indicates a close-ended survey question with response options collapsed for presentation purposes

${ }^{\mathrm{b}}$ For this item, pediatricians and family therapists were queried in different ways. Pediatricians were explicitly asked if funding for screening and referral would increase their use of screening whereas family therapists had to identify funding as a facilitator in response to an open-ended prompt (given that they are able to bill for SRP-related intervention). Pediatricians' responses to the open-ended prompt are in the Study 2 Supplemental Materials

${ }^{*} p<.05 ; * * p<.01 ; * * * p<.001 ;$ all using $\chi^{2}$ test

\section{Provider Factors and Inner Setting}

Several results highlight a critical implementation need to coordinate pediatrician and family therapist SRP services. Both sets of professionals cited a need for referral contacts. Also, several barriers that were prevalent for pediatricians (lack of time, workflow, and concerns with compliance and parental support) were not concerns for family therapists. All of these barriers could be overcome if family therapist staff conducted SRP during well-child visits and provide "warm hand-offs," which are more effective than general practitioner referral (Babor et al., 2017; Walter et al., 2019). Although co-locating behavioral specialists in primary care is not common, it is a widely supported innovation (AAP, 2019). Well-child visit SRPs could generate revenue for pediatricians, whose practices often yield net financial losses (Farmer et al., 2016). Medicaid reimbursement requires
25 min for screening and brief intervention (HCPCS code H0049), which is prohibitive for pediatricians but reasonable for behavioral specialists. Lastly, family therapists, but not pediatricians $(p<0.001)$, reported need for SRP training (91.3\% were interested in training). Family therapist SRP training could include preparing them for well-child SRP, delivering prevention, working within the pediatric office "workflow" (a concern for $66.9 \%$ of pediatricians), and connecting them with pediatricians who are interested in offering SRP.

\section{Outer Setting}

The most prevalent outer setting facilitator for pediatricians is reimbursement for SRP services (86.6\%). Evidence that over $\$ 327 \mathrm{M}$ in annual hospital charges stem from risky behaviors, along with our preliminary post hoc estimate that 
SRP with family-based prevention would cost less than $10 \%$ of those charges, suggests high potential for cost savings from SRP, if hospital charges could be reduced by preventing risky health behaviors. Our annual SRP costs are likely an overestimate because it assumes full participation of all 12-year-olds in SRP and prevention services. Also, individually tailored, family prevention is among the most expensive programs that could be offered (e.g., compared to group or virtual, self-paced computerized programs). Even so, a costsavings model assumes that prevention of risky behaviors would also reduce hospital charges, and the veracity of this assumption remains unknown.

Other outer setting factors included referral sources (see "Provider Factors" discussion), client need for SRP, and patient transportation. Both professions reported about 1/3 of the youths they service engage in risky behaviors, and over $70 \%$ of pediatricians reported "many or most" of their patients would benefit from SRP, suggesting high need for this service. Engaging and retaining prevention recipients is often challenging and could itself be an important focus of implementation. Regarding client transportation as a barrier, multiple prevention programs including Family Check-Up can be delivered virtually, although best practices for this venue are still evolving (Hoffnung et al., 2021; Mauricio et al., 2021). Virtual delivery of behavioral health services is currently reimbursable due to policy changes in response to COVID-19 social distancing (Whaibeh et al., 2020).

Among the risky behavior categories we studied, the greatest potential for accruing healthcare cost savings would be from reducing services for adolescent substance use, risky sex, and externalizing behaviors (Table 2) and would most likely impact costs for inpatient and emergency department visits (Table 1). Externalizing behaviors and high propensity for risky health behaviors can be detected prior to adolescence and youths with one form of risky behavior often develop other risky behaviors (Jessor, 2014; Ridenour et al., 2015). Thus, early detection of high risk, selective intervention, and indicated intervention all offer potential strategies for preventing risky health behaviors and related hospital costs. These studies were based on SRP during pediatric well-child visits. Important implementation questions include whether SRP in other primary care settings (e.g., school-based health centers) could expand the types of youths who access SRP and prevention services and how SRP delivery may differ logistically in other settings. Long-term follow-ups of SRP recipients could test impact on healthcare services they receive (relative to controls) as outcomes. Ideally, cost estimates of these follow-ups would be conducted in partnership with healthcare providers or payors to obtain evidence on cost savings.

\section{Limitations}

Regarding Study 1, long-term impact of prevention on healthcare charges could not be directly computed due to lack of such data (although simulation studies demonstrate cost benefits of prevention across settings in aggregate; Kuklinski et al., 2021). Thus, we estimated cost-savings needed to yield a positive return on SRP investment using the most complete available data. Efficacies of many family-based prevention programs are greater for long-term than short-term outcomes; (De Graaf et al., 2008; Van Ryzin et al., 2012). So, expecting that prevention at age 12 could yield impacts on risky behaviors for many subsequent years is realistic. Also, individual ICD-9 codes vary in how closely they reflect risky behaviors (e.g., a gun-related injury may result from an accident rather than voluntary firearm use), and some healthcare visits that were not included may stem from risky behavior (e.g., Type 1 diabetes that is exacerbated by alcohol use). Errors of omission or commission of hospital visits, services, and charges that stemmed from risky behavior could not be determined. Moreover, our accounting approach to SRP costs does not consider uncertainty due to false positive screens, no shows, variation in intervention efficacy, or other factors. Our 2012-based hospital charges likely underestimate healthcare services and charges because we intentionally avoided costs associated with the ongoing synthetic opioid epidemic (for generalizability of results beyond the epidemic).

Regarding Study 2, survey response rates cannot be determined because emails may have been triaged to "junk" or otherwise not read by recipients. Even so, sample demographics resembled state and national databases. To reduce potential for bias, the stratified sample resembled NC in terms of region and urbanicity. Also, the respective subsamples are relatively homogeneous groups (e.g., professionals, high levels of education, and at least adequate incomes). Similar workforce surveys of these professions were considered representative with samples of only $11 \%$ of these populations (Beck et al., 2017).

\section{Next Steps}

A critical next step is efficacy research to test SRP impact on risky behavior hospital visits and costs. At least three ongoing studies are testing implementation of screening, referral, and/or prevention for risky behaviors in primary care, albeit at different ages (Catalano et al., 2018; Galan et al., 2021; Prado et al., 2019). They also may address the second critical step - testing implementation strategies that support successful screening and prevention. Our study results also suggest testing implementation models to co-locate family behavior specialists in well-child visits including specific modules for their training. 
In sum, we reported evidence that pediatricians and family therapists widely support, see need for, and are interested in SRP and prevention for risky behaviors. Facilitators to implement well-child SRP and intervention were identified. One barrier to SRP is services reimbursement; our estimates support testing whether and how much SRP reduces hospital visits and charges (in turn potentially supporting a cost-savings model for payors of healthcare). Collectively, results of this investigation strongly support further research to develop healthcare-based SRP.

Supplementary Information The online version contains supplementary material available at https://doi.org/10.1007/s11121-021-01321-9.

Funding This study was supported by grants from National Center for Advancing Translational Sciences CTSI (550KR101512) and the National Institute of Drug Abuse (R01 036628).

\section{Declarations}

Ethics Approval This study was approved by the Institutional Review Boards of UNC, Chapel Hill and RTI International. All procedures with human subjects were performed in accordance with the ethical standards of the institute and with the 1964 Helsinki declaration and its later amendments or comparable ethical standards.

Informed Consent The authors confirm that informed consent was obtained from survey participants.

Disclaimer The content herein is solely the responsibility of the authors and do not necessarily reflect views of the National Institutes of Health.

Competing Interests The authors declare no competing interests.

\section{References}

AAP. (2019). National Resource Center for Patient/Family-Centered Medical Home. https://medicalhomeinfo.aap.org/Pages/default. aspx. Accessed 10 May 2020.

AAP. (2010). Committee on substance abuse. Policy statement - alcohol use by youth and adolescents: a pediatric concern. Pediatrics, 125 , 1078-1087.

Agency for Health Research and Quality. (2012). Healthcare Cost Utilization Project cost-to-charge ratio file, 2012.

American Board of Pediatrics. (2017). Pediatric Physicians Workforce Data Book, 2016-2017, Chapel Hill, NC: American Board of Pediatrics.

American Society of Addiction Medicine. (2017). Reimbursement for SBIRT. Retrieved on 8 June 2021 from: https://www.asam. org/docs/default-source/education-docs/sbirt-reimbursement-allpayer-overview_02-20177fa32b9472bc604ca5b7ff000030b21a. pdf?sfvrsn $=\mathrm{f} 41 \mathrm{f} 4 \mathrm{bc} 2 \_0$

Babor, T. F., Del Boca, F., \& Bray, J. W. (2017). Screening, brief intervention and referral to treatment: Implications of SAMHSA's SBIRT initiative for substance abuse policy and practice. Addiction, 112, 110-117.

Beck, A. J., Singer, P. M., \& Buche, J. (2017). Minimum data sets for behavioral health workers: an implementation pilot. https:// www.behavioralhealthworkforce.org/wp-content/uploads/2018/ 02/Y2FA1_MDS_Full-Report.pdf. Accessed 14 Nov 2020.

Catalano, R. F., Kuklinski, M., \& Sterling, S. (2018). Guiding Good Choices for Health (GGC4H): Testing feasibility and effectiveness of universal parent-focused prevention in three healthcare systems. https://rethinkingclinicaltrials.org/news/. Accessed 18 May 2020.

Cawley, J., \& Ruhm, C. J. (2011). The economics of risky health behaviors. In Handbook of health economics (Vol. 2, pp. 95-199). Elsevier.

CMS Innovation Center. (2020). Integrated care for kids model. https:// www.innovation.cms.gov/innovation-models/integrated-care-forkids-model. Accessed 10 May 2020.

Damschroder, L. J., Aron, D. C., Keith, R. E., Kirsh, S. R., Alexander, J. A., \& Lowery, J. C. (2009). Fostering implementation of health services research findings into practice: a consolidated framework for advancing implementation science. Implementation Science, $4,50$.

De Graaf, I., Speetjens, P., Smit, F., De Wolff, M., \& Tavecchio, L. (2008). Effectiveness of the Triple P Positive Parenting Program on behavioral problems in children: a meta-analysis. Behavior Modification, 32, 714-735.

Farmer, S. A., Shalowitz, J., George, M., McStay, F., Patel, K., Perrin, J., Moghtaderi, A., \& McClellan, M. (2016). Fully capitated payment breakeven rate for a mid-size pediatric practice. Pediatrics, 138(2).

FPGCDI. (2020). North Carolina Implementation Capacity for Triple P (NCIC-TP). https://fpg.unc.edu/projects/north-carolinaimplementation-capacity-triple-p-ncic-tp

Galan, C. A., Shaw, D. S., O'Rourke, F., Reynolds, M. D., Gill, A., Bogen, D. L., \& Ridenour, T. A. (2021). The Family Check-Up in primary care to prevention adolescent substance use and antisocial behavior [Manuscript submitted for publication].

Hales, C. M., Fryar, C. D., Carroll, M. D., Freedman, D. S., \& Ogden, C. L. (2018). Trends in obesity and severe obesity prevalence in US youth and adults by sex and age, 2007-2008 to 2015-2016. JAMA, 319, 1723-1725.

HCUP. (2019). Healthcare Cost and Utilization Project Databases. Rockville, MD: Agency for Healthcare Research and Quality.

Hinde, J., Bray, J., Kaiser, D., \& Mallonee, E. (2017). The influence of state-level policy environments on activation of Medicaid SBIRT reimbursement codes. Addiction, 112, 82-91.

Hoffnung, G., Feigenbaum, E., Schechter, A., Guttman, D., Zemon, V., \& Schechter, I. (2021). Children and telehealth in mental healthcare: what we have learned from COVID-19 and 40,000+ sessions. Psychiatric Research and Clinical Practice.

Jessor, R. (2014). Problem behavior theory: a half-century of research on adolescent behavior development. In R. M. Lerner, A. C. Petersen, R. K. Silbereisen, \& J. Brooks-Gunn (Eds.), The Developmental Science of Adolescence (pp. 239-256). Psychology Press.

Johnston, L., Miech, R., O’Malley, P., Bachman, J., Schulenberg, J., \& Patrick, M. (2020). Monitoring the future national survey results drug use 1975-2019: Overview, key findings on Social, adolescent drug use.

Kim, J. Y., Asrani, S. K., Shah, N. D., Kim, W. R., \& Schneekloth, T. D. (2012). Hospitalization for underage drinkers in the United States. Journal of Adolescent Health, 50, 648-650.

Kuklinski, M. R., Oesterle, S., Briney, J. S., \& Hawkins, J. D. (2021). Long-term impacts and benefit-cost analysis of the communities that care prevention system at age 23, 12 years after baseline. Prevention Science, 22, 452-463.

Levy, S., \& Kokotailo, P. K. (2011). Substance use screening, brief intervention, and referral to treatment for pediatricians. Pediatrics, 128, e1330-e1340.

Levy, S., Ziemnik, R. E., Harris, S. K., Rabinow, L., Breen, L., Fluet, C., et al. (2017). Screening adolescents for alcohol use: Tracking 
practice trends of Massachusetts pediatricians. Journal of Addiction Medicine, 11, 427-434.

Mauricio, A. M., Rudo-Stern, J., Dishion, T. J., Shaw, D. S., Gill, A. M., Lundgren, J. S., \& Thunberg, J. (2021). Facilitators and barriers in cross-country transport of evidence-based preventive interventions. Prevention Science, 22, 73-83.

McGee, V., \& Fraher, E. (2012). The state of racial/ethnic diversity in North Carolina's health workforce. NoRth Carolina Medical Journal, 73, 337-345.

Moorman, J. E., Zahran, H., Truman, B. I., Molla, M. T., \& Centers for Disease Control and Prevention (CDC). (2011). Current asthma prevalence-United States, 2006-2008. MMWR Surveillance Summaries, 60, 84-86.

Moyer, V. A., \& USPSTF. (2013). Screening and behavioral counseling interventions in primary care to reduce alcohol misusE: U.S. Preventive Services Task Force recommendation statement. Annals of Internal Medicine, 159(3), 210-8.

National Institute on Drug Abuse. (2020). Costs of substance abuse. https://www.drugabuse.gov/drug-topics/trends-statistics/costssubstance-abuse. Accessed 13 Nov 2020.

NC Demographic Statistics. (2020). Infoplease. https://www.infoplease. com/us/comprehensive-census-data-state/demographic-statistics236. Accessed 18 May 2020.

NC DMA. (2018). NC DMA Health Check Program Guide. https:// www.hcup-us.ahrq.gov/databases.jsp. Accessed 22 Jan 2020.

North Carolina Population. (2020). World Population Review. https:// worldpopulationreview.com/states/north-carolina-population/. Accessed 18 May 2020.

O’Connor, K. (2019). Triple P - Positive Parenting Program. https:// files.nc.gov/ncdhhs/documents/files/dss/dcdl/childwelfareservices/ CWS-01-2019.pdf. Accessed 10 May 2020.

Ozechowski, T. J., Becker, S. J., \& Hogue, A. (2016). SBIRT-A: Adapting SBIRT to Maximize Developmental Fit for Adolescents in Primary Care. Journal of Substance Abuse Treatment, 62, 28-37.

Pettitt, D. J., Talton, J., Dabelea, D., Divers, J., Imperatore, G., Lawrence, J. M., Liese, A.D., Linder, B., Mayer-Davis, E. J., Pihoker, C., Saydah, S. H., \& SEARCH for Diabetes in Youth Study Group. (2014). Prevalence of diabetes in US youth in 2009: the SEARCH for diabetes in youth study. Diabetes care, 37(2), 402-408.

Prado, G., Estrada, Y., Rojas, L. M., Bahamon, M., Pantin, H., Nagarsheth, M., et al. (2019). Rationale and design for eHealth Familias Unidas Primary Care: a drug use, sexual risk behavior, and STI preventive intervention for hispanic youth in pediatric primary care clinics. Contemporary Clinical Trials, 76, 64-71.

Redfield, R. R., Kent, C. K., Leahy, M. A., Martinroe, J. C., Spriggs, S. R., Yang, T., et al. (2017). Morbidity and Mortality Weekly Report Centers for Disease Control and Prevention MMWR Editorial and Production Staff (Serials) MMWR Editorial Board.

Ridenour, T. A., Willis, D., Bogen, D. L., Novak, S., Scherer, J., Reynolds, M. D., et al. (2015). Detecting initiation or risk for initiation of substance use before high school during pediatric well-child checkups. Drug and Alcohol Dependence, 150, 54-62.

Selden, T. M. (2006). Compliance with well-child visit recommendations: Evidence from the Medical Expenditure Panel Survey, 2000-2002. Pediatrics, 118, e1766-e1778.

Singh, M., Gmyrek, A., Hernandez, A., Damon, D., \& Hayashi, S. (2017). Sustaining Screening, Brief Intervention and Referral to Treatment (SBIRT) services in health-care settings.

Sonfield, A., \& Kost, K. (2015). Public costs from unintended pregnancies and the role of public insurance programs in paying for pregnancy-related care. https://www.guttmacher.org

Stanhope, V., Manuel, J. I., Jessell, L., \& Halliday, T. M. (2018). Implementing SBIRT for adolescents within community mental health organizations: a mixed methods study. Journal of Substance Abuse Treatment, 90, 38-46.

Sterling, S., Kline-Simon, A. H., Satre, D. D., Jones, A., Mertens, J., et al. (2015). Implementation of screening, brief intervention, and referral to treatment for adolescents in pediatric primary care a cluster randomized trial. JAMA Pediatrics, 169, e153145.

Sterling, S., Kline-Simon, A. H., Wibbelsman, C., Wong, A., \& Weisner, C. (2012). Screening for adolescent alcohol and drug use in pediatric health-care settings: Predictors and implications for practice and policy. Addiction Science \& Clinical Practice, 7, 13.

Tanner-Smith, E. E., \& Lipsey, M. W. (2015). Brief alcohol interventions for adolescents and young adults: a systematic review. Journal of Substance Abuse Treatment, 51, 1-18.

US Bureau of Labor Statistics. (2019). Consumer Price Index. https:// www.bls.gov/cpi/. Accessed 27 Feb 2020.

Van Hook, S., Harris, S. K., Brooks, T., Carey, P., Kossack, R., Kulig, J., \& Knight, J. R. (2007). The Six T's: Barriers to screening teens for substance abuse in primary care. Journal of Adolescent Health, 40, 456-461.

Van Ryzin, M. J., Stormshak, E. A., \& Dishion, T. J. (2012). Engaging parents in the family check-up in middle school: Longitudinal effects on family conflict and problem behavior through the high school transition. Journal of Adolescent Health, 50, 627-633.

Vendetti, J., Gmyrek, A., Damon, D., Singh, M., Mcree, B., \& Del Boca, F. (2017). Screening, brief intervention and referral to treatment (SBIRT). Addiction, 112, 23-33.

Walter, H. J., Vernacchio, L., Trudell, E. K., Bromberg, J., Goodman, E., Barton, J., et al. (2019). Five-year outcomes of behavioral health integration in pediatric primary care. Pediatrics, 144 .

Whaibeh, E., Mahmoud, H., \& Naal, H. (2020). Telemental health in the context of a pandemic: The COVID-19 experience. Current Treatment Options in Psychiatry, 7, 198-202.

Publisher's Note Springer Nature remains neutral with regard to jurisdictional claims in published maps and institutional affiliations. 